\title{
American College of Medical Genetics and Genomics guideline for the clinical evaluation and etiologic diagnosis of hearing loss
}

\author{
Raye L. Alford, PhD, FACMG ${ }^{1}$, Kathleen S. Arnos, PhD, FACMG², Michelle Fox, MS, CGC 3,4, \\ Jerry W. Lin, MD, PhD ${ }^{1}$, Christina G. Palmer, PhD, FACMG5,6, Arti Pandya, MD, FACMG ${ }^{7}$, \\ Heidi L. Rehm, PhD, FACMG ${ }^{8}$, Nathaniel H. Robin, MD, FACMG ${ }^{9}$, Daryl A. Scott, MD, PhD ${ }^{10,11}$ \\ and Christine Yoshinaga-Itano, PhD ${ }^{12}$; ACMG Working Group on Update of Genetics Evaluation \\ Guidelines for the Etiologic Diagnosis of Congenital Hearing Loss; for the Professional Practice \\ and Guidelines Committee
}

\begin{abstract}
Disclaimer: This guideline is designed primarily as an educational resource for clinicians to help them provide quality medical services. Adherence to this guideline is completely voluntary and does not necessarily assure a successful medical outcome. This guideline should not be considered inclusive of all proper procedures and tests or exclusive of other procedures and tests that are reasonably directed to obtaining the same results. In determining the propriety of any specific procedure or test, the clinician should apply his or her own professional judgment to the specific clinical circumstances presented by the individual patient or specimen. Clinicians are encouraged to document the reasons for the use of a particular procedure or test, whether or not it is in conformance with this guideline. Clinicians also are advised to take notice of the date this guideline was adopted, and to consider other medical and scientific information that becomes available after that date. It also would be prudent to consider whether intellectual property interests may restrict the performance of certain tests and other procedures.
\end{abstract}

Hearing loss is a common and complex condition that can occur at any age, can be inherited or acquired, and is associated with a remarkably wide array of etiologies. The diverse causes of hearing loss, combined with the highly variable and often overlapping presentations of different forms of hearing loss, challenge the ability of traditional clinical evaluations to arrive at an etiologic diagnosis for many deaf and hard-of-hearing individuals. However, identifying the etiology of a hearing loss may affect clinical management, improve prognostic accuracy, and refine genetic counseling and assessment of the likelihood of recurrence for relatives of deaf and hard-of-hearing individuals. Linguistic and cultural identities associated with being deaf or hard of hearing can complicate access to and the effectiveness of clinical care. These concerns can be minimized when genetic and other health-care services are provided in a linguistically and culturally sensitive manner. This guideline offers information about the frequency, causes, and presentations of hearing loss and suggests approaches to the clinical evaluation of deaf and hard-of-hearing individuals aimed at identifying an etiologic diagnosis and providing informative and effective patient education and genetic counseling.

Genet Med advance online publication 20 March 2014

Key Words: genetics evaluation; deaf; Deaf; genetic counseling; genetic testing; guideline; hard of hearing; hearing loss

\section{DEFINITIONS}

Deaf: a community with a distinct culture and language shaped by the experience of being deaf or hard of hearing, which may include deaf, hard-of-hearing, and hearing individuals

deaf: an auditory phenotype characterized by a total or neartotal loss of the ability to hear hard of hearing: an auditory phenotype characterized by a partial loss of the ability to hear

hearing loss: an auditory phenotype characterized by any degree of loss of the ability to hear; depending on cause, hearing loss can be temporary or permanent-this guideline focuses on permanent hearing loss

\footnotetext{
${ }^{1}$ Bobby R. Alford Department of Otolaryngology-Head and Neck Surgery, Baylor College of Medicine, Houston, Texas, USA; ${ }^{2}$ Department of Science, Technology, and Mathematics, Gallaudet University, Washington, DC, USA; ${ }^{3}$ Department of Pediatrics, David Geffen School of Medicine, University of California, Los Angeles, Los Angeles, California, USA; ${ }^{4}$ Department of Genetics, David Geffen School of Medicine, University of California, Los Angeles, Los Angeles, California, USA; ${ }^{5}$ Department of Psychiatry and Biobehavioral Sciences, David Geffen School of Medicine, University of California, Los Angeles, Los Angeles, California, USA; ${ }^{6}$ Department of Human Genetics, David Geffen School of Medicine, University of California, Los Angeles, Los Angeles, California, USA; ${ }^{7}$ Department of Human and Molecular Genetics, Virginia Commonwealth University, Richmond, Virginia, USA; ${ }^{8}$ Laboratory for Molecular Medicine, Harvard Medical School, Cambridge, Massachusetts, USA; ${ }^{9}$ Department of Genetics, University of Alabama at Birmingham, Birmingham, Alabama, USA; ${ }^{10}$ Department of Molecular and Human Genetics, Baylor College of Medicine, Houston, Texas, USA; ${ }^{11}$ Department of Molecular Physiology and Biophysics, Baylor College of Medicine, Houston, Texas, USA; ${ }^{12}$ School of Medicine, University of Colorado Denver, Aurora, Colorado, USA. Correspondence: Raye L. Alford (ralford@bcm.edu)
} 


\section{INTRODUCTION}

Two to three of every 1,000 children born in the United States are deaf or have a hearing loss significant enough to affect speech and language development. ${ }^{1}$ Early intervention has been shown to be effective in facilitating speech and language development in deaf and hard-of-hearing children. ${ }^{2}$ As a result, newborn hearing screening, which began in 2001, is now mandated throughout the United States. Not all childhood hearing loss is present at birth, however, and hearing screening is recommended throughout childhood and adolescence to identify children with lateronset hearing loss and to permit early intervention., ${ }^{3,4}$

Ninety-five percent of newborns with hearing loss identified by newborn hearing screening programs are born to hearing parents, obscuring the fact that the majority of newborns have a hereditary cause for their hearing loss. ${ }^{5,6}$ Analysis of family history data from school-aged children in the United States estimated that up to $60 \%$ of educationally significant congenital and early-onset hearing loss is caused by genetic factors. ${ }^{5,6}$ The majority of genetic hearing loss is inherited in an autosomal recessive pattern and often presents in the absence of a positive family history for hearing loss. One gene, GJB2, which encodes the gap junction protein connexin 26, accounts for the largest proportion of autosomal recessive early childhood hearing loss in many populations. ${ }^{7}$

The prevalence of hearing loss increases with age, with 40 $50 \%$ of the population experiencing hearing loss by age $75 .{ }^{8}$ The contribution of genetic causes to cases of adult-onset hearing loss is less clear. However, it is evident that a significant proportion of adult-onset hearing loss is likely to be caused, or strongly influenced, by genetic factors. ${ }^{9-14}$

The goal of a genetics evaluation for deaf and hard-of-hearing individuals of any age is to identify an etiologic diagnosis and, in doing so, enable implementation of an individualized health-maintenance strategy. ${ }^{15-17}$ Identification of a previously unrecognized syndromic form of hearing loss can be particularly important because it may allow early management of associated medical concerns. Obtaining an etiologic diagnosis also provides the basis for precise genetic counseling that includes an accurate estimation of the chances for recurrence of hearing loss within families.

\section{AUDIOMETRIC AND CLINICAL ASPECTS OF HEARING LOSS}

Hearing loss is typically described in terms related to its clinical presentation. In general, hearing loss is categorized as either syndromic or nonsyndromic, depending on the presence or absence of associated defects in other organ systems. Hearing loss is also typically described by the following:

- The age of onset-congenital, prelingual (before the acquisition of speech), postlingual (after the acquisition of speech), adult-onset, or presbycusis (age-related lateonset hearing loss);

- The type of hearing loss-sensorineural, conductive, mixed, or auditory neuropathy;
- The laterality and symmetry of the hearing loss-unilateral or bilateral, symmetric or asymmetric;

- The stability of the hearing loss-progressive, nonprogressive, or fluctuating;

- The degree of hearing loss-slight (16-25 decibels (dB)), mild (26-40 dB), moderate (41-55 dB), moderately severe (56-70 dB), severe (71-90 dB), or profound (91 dB or greater) ${ }^{18}$; and

- The configuration of the hearing loss as seen on audiometric analysis-sloping, flat, rising, or midfrequency (cookie-bite) loss.

Hearing loss may also be described according to an apparent pattern of inheritance-autosomal recessive, autosomal dominant, X-linked, or matrilineal (mitochondrial). If a specific etiology is known, descriptions of hearing loss may also include the etiologic diagnosis, such as Usher syndrome type 1-related hearing loss or GJB2-related hearing loss. ${ }^{15,16,19,20}$

\section{GENETIC AND NONGENETIC ETIOLOGIES OF HEARING LOSS}

Hearing loss is among the most etiologically heterogeneous disorders, with more than 400 genetic syndromes that include hearing loss as a feature, more than 100 genes associated with nonsyndromic genetic hearing loss, and a number of nongenetic causes. ${ }^{20,21}$ Genes associated with syndromic and nonsyndromic genetic hearing loss encode a variety of proteins involved in the development and function of the auditory system, including transcription factors, structural proteins, gap junction proteins, and ion channels, to name just a few.

An estimated $30 \%$ of genetic hearing loss is syndromic. A few syndromes, such as Pendred (enlarged vestibular aqueduct, thyroid problems), Usher (retinitis pigmentosa), Waardenburg (pigmentary anomalies), and branchio-oto-renal (branchial arch and renal anomalies) syndromes, account for substantial percentages of hearing loss in some populations..$^{20,22-25}$ Syndromic hearing loss may be transmitted as an autosomal recessive, autosomal dominant, $\mathrm{X}$-linked, or matrilineal trait. A review of individual conditions can be found in Hereditary Hearing Loss and Its Syndromes by Toriello and Smith ${ }^{20}$ and the online database GeneReviews. ${ }^{19}$

For some syndromic forms of hearing loss, such as Usher syndrome or Pendred syndrome, the nonauditory features can be subtle, especially in early childhood. For others, hearing loss is not the presenting finding or the most pressing concern. For many syndromic forms of hearing loss, there is marked variability in the phenotypic presentation and in the age of onset of syndromic features. This variability can exist both between and within families. For example, hearing loss is observed in only $20-50 \%$ of individuals with Waardenburg syndrome. As a result, this diagnosis can be easily missed if specific information about pigmentary changes or gastrointestinal disturbances is not elicited. ${ }^{26}$ Furthermore, some hereditary forms of hearing loss, such as neurofibromatosis type 2 , enlarged vestibular aqueduct syndrome, and Pendred syndrome, may present 
initially as unilateral hearing loss..$^{19,20,27-29}$ Given the challenges that can exist in distinguishing between syndromic and nonsyndromic forms of hearing loss, all children and adolescents showing hearing loss without a known etiology, e.g., confirmed GJB2 mutations or documented congenital cytomegalovirus (CMV) infection, should be evaluated for syndromic conditions by a clinical geneticist. ${ }^{15,16}$

An estimated $70 \%$ of genetic hearing loss is nonsyndromic. Nonsyndromic hearing loss may be transmitted as an autosomal recessive $(\sim 80 \%)$, autosomal dominant $(\sim 15 \%)$, or X-linked trait $(\sim 1 \%) .{ }^{20}$ In addition, matrilineal (mitochondrial) transmission of nonsyndromic hearing loss occurs with a frequency of $\sim 1 \%$ in Western nations but has a slightly higher incidence in Spain and East Asian countries including China, Mongolia, Korea, and Japan. ${ }^{30,31}$

Of particular note, the DFNB1 locus, which includes the GJB2 gene encoding the gap junction protein connexin 26 and the GJB6 gene encoding the gap junction protein connexin 30, accounts for an estimated $50 \%$ of all autosomal recessive nonsyndromic hearing loss and $15-40 \%$ of all deaf individuals in a variety of populations. ${ }^{7,32-38}$ More than 150 deafness-causing variants have been identified in GJB2, but a few common mutations account for a large percentage of alleles in several populations. ${ }^{7,34-36} \mathrm{GJB2}$-related hearing loss is sensorineural, usually present at birth, typically bilateral and nonprogressive, and can range from mild to profound in severity. However, progressive or later-onset hearing loss-with infants passing their newborn hearing screen-have also been described, particularly in association with nontruncating mutations. ${ }^{39-42}$ Nonsyndromic hearing loss due to mutations at the DFNB1 locus may also be caused by (i) interaction of a GJB2 mutation on one allele and a deletion involving GJB6 on the other allele or (ii) biallelic deletions involving GJB6. ${ }^{43-45}$ GJB6 deletions have been observed in multiple populations, although they appear to be a relatively uncommon explanation for hearing loss in the United States. ${ }^{46-48}$ Notably, hearing loss caused by certain dominant mutations in GJB2, although uncommon, may present as a syndromic hearing loss, with associated skin findings. ${ }^{49-51}$

Nonsyndromic mitochondrial hearing loss is characterized by audiograms that fall into the moderate-to-profound range and is associated with variants in either the MT-RNR1 gene encoding the mitochondrial $12 \mathrm{~S}$ ribosomal RNA or the MT-TS1 gene encoding the mitochondrial transfer RNA Ser(UCN) ${ }^{30,31,52}$ Of particular note, mutations in MT-RNR1 are associated with predisposition to aminoglycoside ototoxicity. ${ }^{53}$ Hearing loss in individuals exposed to aminoglycoside antibiotics who carry susceptibility mutations in MT-RNR1 is bilateral, severe to profound, and typically develops within a few days to weeks after administration of any amount, including just a single dose, of an aminoglycoside antibiotic. ${ }^{54}$ Studies offer conflicting findings with regard to the likelihood of hearing loss in individuals carrying a deafness-causing variant in MT-RNR1 who are not exposed to aminoglycosides. ${ }^{53-55}$

Age-related hearing loss, or presbycusis, is a common neurosensory deficit. In the United States, presbycusis is present in $40-50 \%$ of individuals aged 75 and older. Presbycusis generally affects higher frequencies of sound disproportionately, making it difficult for those with presbycusis to understand speech. ${ }^{8}$ Men have presbycusis more frequently than women. ${ }^{56}$ Presbycusis is a complex condition influenced by genetic and environmental factors. ${ }^{13}$ Much of the literature about age-related hearing loss has focused on environmental factors such as noise exposure. ${ }^{9,57,58}$ More recently, however, several susceptibility loci for age-related hearing loss have been identified. Genes implicated in this process using linkage and genome-wide association studies include genes previously implicated in other forms of hearing loss (such as KCNQ4 and ACTG1), and genes involved in oxidative stress (such as GRM7, GRHL2, mitochondrial oxidative genes, and $\mathrm{N}$-acetyltransferase). ${ }^{9,10,12-14,20}$

Certain environmental (nongenetic) factors play a major etiologic role in hearing loss. ${ }^{59}$ In the United States, congenital CMV infection is the most common nongenetic cause of hearing loss among children. Of the 20,000-40,000 infants born with congenital CMV infection each year, $90 \%$ have no detectable clinical abnormalities at birth, yet $10-15 \%$ of these asymptomatic infants will develop sensorineural hearing loss which can present in early childhood, can be unilateral or bilateral, and is often progressive. ${ }^{60-62}$ As a result, congenital CMV infection may go undetected even in children who undergo newborn hearing screening and receive a thorough physical examination in the neonatal period. ${ }^{16,20,62}$

Congenital rubella, which was a common cause of hearing loss in the mid-1960s, occurs less frequently in Western populations today as a result of successful immunization programs. ${ }^{63,64}$ According to the World Health Organization, no cases of endemic rubella infection are known to have occurred in the Americas between 2009 and 2012. ${ }^{65}$ Similarly, the occurrence of postmeningitic hearing loss in children has been substantially reduced in developed countries as a result of vaccination against Haemophilus influenzae. ${ }^{66}$ However, other environmental causes for hearing loss-including prematurity and exposure to noise or ototoxic drugs such as aminoglycosides and cyclophosphamides (which may have a genetically determined predisposition in some cases)-persist in the United States today. ${ }^{20,67-69}$

\section{THE IMPORTANCE OF GENETIC EVALUATION AND GENETIC COUNSELING FOR DEAF AND HARD-OF-HEARING INDIVIDUALS}

When a genetic etiology is possible, a clinical genetics evaluation, including genetic counseling, offers a number of potential benefits for children and adults with hearing loss and their families. Benefits can include providing etiologic information, identifying (or allaying concerns about) comorbidities that may need referral for specialty care, planning for future medical and educational needs, facilitating estimations of the likelihood of recurrence, allowing families to better plan for the birth of a deaf or hard-of-hearing child, relieving the guilt that some parents may feel about having a child with hearing loss, enhancing 
psychological well-being, dispelling misinformation, and facilitating referral for unrelated hereditary conditions such as familial cancer. ${ }^{48,70-79}$ Furthermore, if mitochondrial DNA mutations associated with genetic susceptibility to aminoglycoside ototoxicity are discovered, it may be possible for relatives to avoid precipitating medications. ${ }^{53-55}$

As with any genetics evaluation, clear communication between the genetics professionals and their patients is important for the provision of effective genetics services. Deaf and hard-of-hearing individuals use a variety of communication methods, including spoken and signed language, lip reading, and written notes. Special training may be needed to optimize communication between individuals with hearing loss and genetics professionals. Such training may include (i) training sign language interpreters in medical and genetics terminology and (ii) training genetics professionals to work effectively with sign language interpreters and use a variety of communication aids, including videophones, video relay services, instant messaging, and visual aids. ${ }^{80}$

In addition, deafness is considered by some to be a nonmedical trait. Many deaf individuals consider themselves to be part of a linguistic and cultural minority group, viewing their deafness as a neutral or positive trait. ${ }^{81,82}$ By contrast, the medical perspective-which views deafness as a pathology-is pervasive among most hearing individuals and some deaf individuals. This difference in perspective may affect the willingness of some individuals to obtain genetic services and genetic counseling. ${ }^{83,84}$ However, when given accurate information about the nature of genetic counseling and how to obtain a referral, Deaf adults are often interested in receiving genetic services in order to learn more about themselves and why they are deaf or hard of hearing. In addition, many Deaf and hard-of-hearing individuals report an enhanced sense of self-understanding and self-identity, as well as an enhanced cultural and group identity, as a result of genetic testing. ${ }^{.2,85}$ Providing genetic services in a linguistically and culturally sensitive manner has been shown to improve outcomes such as genetics knowledge and understanding. ${ }^{86,87}$ Furthermore, using neutral or balanced terminology, such as "chance" instead of "risk," "deaf" or "hearing" instead of "affected" or "unaffected", and exercising caution in the use of terms such as "handicapped," "pathology," and "impairment" can enhance the provision of genetic services to deaf and hard-of-hearing individuals and their families. ${ }^{86,88,89}$

\section{GENETIC TESTING FOR THE ETIOLOGIC DIAGNOSIS OF HEREDITARY HEARING LOSS}

Historically, molecular diagnostic tests for hearing loss have used genotyping or DNA sequencing to identify specific hearing loss variants or to screen individual genes, or small collections of genes, for changes associated with hearing loss. This approach has proven to be effective in cases in which there is a single gene, or limited number of genes, responsible for a subtype of hearing loss. Examples include SLC26A4 gene sequencing in individuals suspected of having Pendred syndrome, $P A X 3$ gene sequencing in individuals with features of Waardenburg syndrome type I, MITF and SOX10 gene sequencing in individuals with features of Waardenburg syndrome type II, or sequencing of MYO7A or USH2A, the most common genes involved in Usher syndrome types I and II, respectively. ${ }^{90,91}$ Such screening can also be cost effective in individuals with genetically heterogeneous hearing loss phenotypes when a single gene is responsible for a significant percentage of cases. For example, GJB2 gene sequencing can identify the underlying etiology for many individuals whose clinical presentation is consistent with autosomal recessive nonsyndromic hearing loss.

Today, tests based on next-generation sequencing (NGS) technologies are rapidly replacing many single gene-sequencing tests for hearing loss (Figure 1). These tests use disease-targeted exon capture, whole-exome sequencing (WES), or wholegenome sequencing (WGS) strategies. The main advantage of these tests is their ability to address the problem of genetic heterogeneity, wherein many different genes result in phenotypes that cannot be easily distinguished clinically. ${ }^{92-96}$ Several NGS tests are now clinically available and can be found by querying the GeneTests and Genetic Testing Registry websites. ${ }^{97,98}$

NGS tests that use disease-targeted exon-capture approaches restrict sequencing to specific genes, such as genes known to be associated with hearing loss. Such tests can provide excellent coverage of the genes selected for study but are limited by our present knowledge of which genes are involved in hearing loss. Furthermore, some tests may sequence only a subset of the genes known to be associated with hearing loss. WES is also based on exon capture but does not rely on a list of genes involved in a particular disease process. Instead, WES seeks to evaluate all exons in the genome for variations. This approach can identify variants in known hearing loss-related genes and genes that have yet to be associated with hearing loss. WGS is not limited to screening exons and therefore has the potential to identify changes outside of exons that may be related to hearing loss.

The ability of WES and WGS approaches to detect a larger subset of all hearing loss-related changes needs to be balanced with the difficulties in interpretation that come from identifying an ever-increasing number of variants, the challenge of causally linking variants in new genes to hearing loss, and the likelihood of identifying genetic susceptibilities unrelated to hearing loss (i.e., incidental findings). ${ }^{99}$ In 2013, the ACMG published recommendations for reporting incidental findings from genomic sequencing. ${ }^{100}$

Furthermore, not all regions of the genome are efficiently captured and analyzed by current exon-capture or WGS approaches, and large deletions and duplications, in addition to copy-number and structural variations, may not be efficiently detected. ${ }^{99}$ These limitations of NGS technologies may necessitate use of alternative or complementary genetic testing strategies in some cases.

NGS technologies are expected to continue to improve over time, but it will always be important to pay close attention to the performance characteristics of tests, including coverage, analytic sensitivity, the genes that are and are not analyzed, and the types of mutations that are and are not detected. In some cases, it may be helpful to have tests performed in laboratories that 


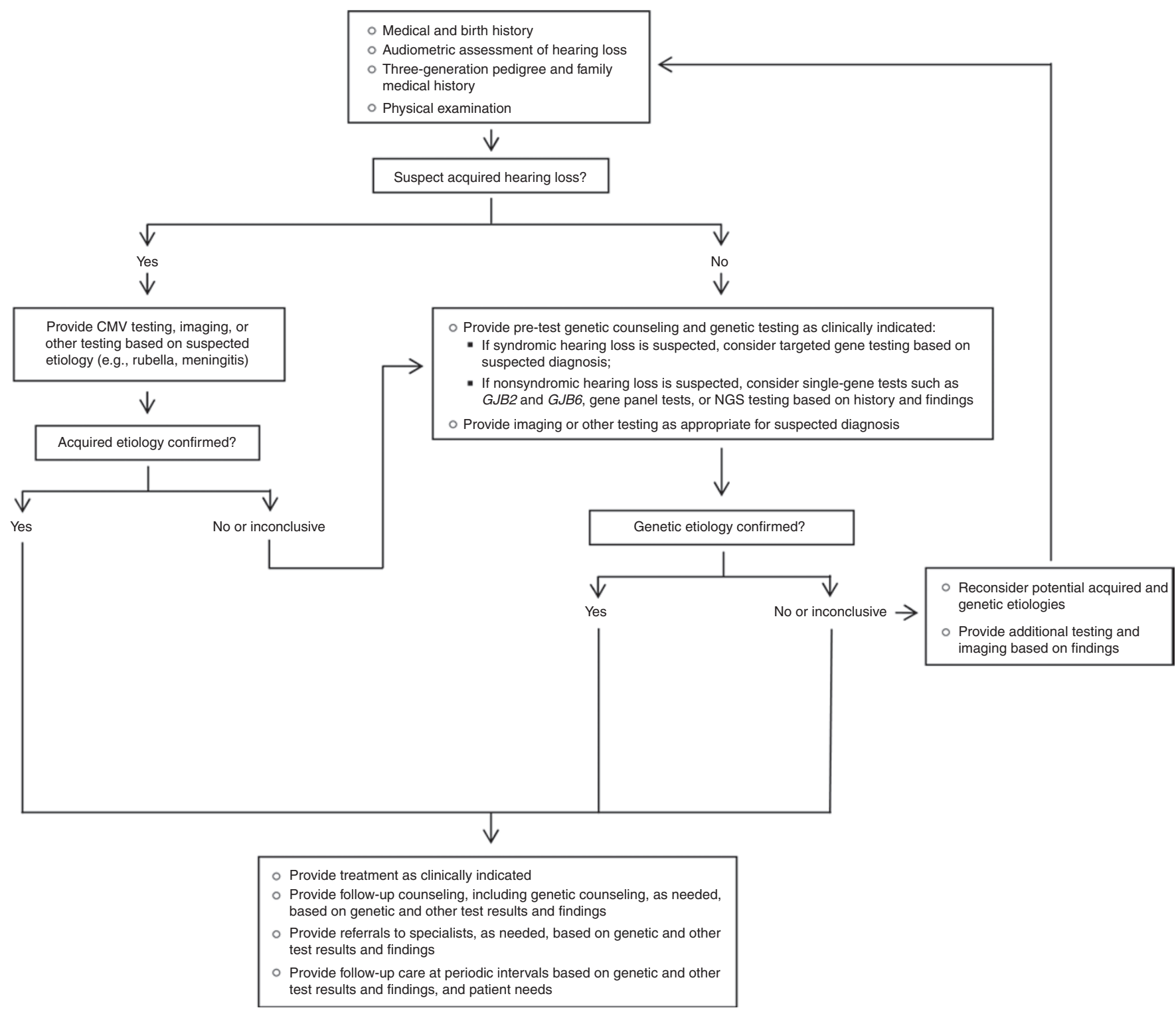

Figure 1 Graphic overview of approaches to the clinical evaluation and etiologic diagnosis of hearing loss. CMV, cytomegalovirus; NGS, nextgeneration sequencing.

focus on genetic causes of hearing loss because these laboratories may be more likely to report test performance with respect to hearing-related genes and to have developed approaches to specifically analyze relevant regions of the genome that may be refractory to more general NGS approaches. ${ }^{92-96,99}$

\section{OTHER TESTING IMPORTANT TO THE ETIOLOGIC DIAGNOSIS OF HEARING LOSS}

Because CMV remains a common cause of pediatric hearing loss, testing for congenital CMV infection by rapid culture or polymerase chain reaction of saliva or urine samples from newborns is recommended as an initial test once a newborn hearing loss is confirmed (Figure 1). However, testing for CMV is most diagnostic when done before $\sim 6$ weeks of age. ${ }^{101-105} \mathrm{~A}$ negative result most likely excludes CMV as the cause of the hearing loss, but a positive result may not necessarily indicate that the hearing loss is due to CMV infection, especially if obtained in older children who may have been exposed to CMV after birth.

Recent algorithms for the evaluation of hearing loss suggest that other nongenetic tests, such as computed tomography, magnetic resonance imaging, renal ultrasonography, electrocardiography, and ophthalmologic consultation, have an important role because their results can guide genetic testing or interpretation of DNA sequence variants. ${ }^{106}$ For example, temporal bone imaging is commonly recommended to look for an enlarged vestibular aqueduct, which would prompt genetic testing for Pendred syndrome. ${ }^{27,107,108}$ However, many nongenetic tests have low diagnostic yield in patients with hearing loss. ${ }^{109}$ Furthermore, recent advances in genetic testing technologies that permit the analysis of many genes simultaneously at rapidly decreasing cost may soon prompt reassessment of the clinical utility of certain nongenetic tests as part of the initial 
workup for the etiologic diagnosis of hearing loss. Such reassessments will need to consider the clinical utility of various nongenetic tests versus the risks associated with those tests, such as the clinical utility of computed tomography and magnetic resonance imaging versus the risks associated with radiation exposure and sedation. ${ }^{17,109}$ As evidence for the clinical utility of NGS tests for the etiologic diagnosis of hearing loss is accumulated and evaluated, physicians should continue to rely on their best clinical judgment and consider the use of nongenetic tests for the evaluation of hearing loss on a case-by-case basis. For example, unless cochlear implantation is being considered, auditory neuropathy is detected, progressive hearing loss is identified, or other specific clinical concerns exist, it could be argued that temporal bone imaging might, in some cases, be better used as a complement or follow-up to genetic testing rather than as a part of the initial diagnostic evaluation. ${ }^{109,110} \mathrm{In}$ addition, in the absence of specific clinical concerns or family history, tests such as electrocardiographic studies, thyroid function testing, urinalysis, and renal ultrasonography might also be postponed until results of genetic testing are obtained, and then ordered as clinically indicated. ${ }^{109,111,112}$

\section{GUIDELINE}

1. All newborns and infants with confirmed hearing loss should undergo a comprehensive evaluation in which patient-focused medical and birth histories and a threegeneration pedigree and family medical history are obtained, and a physical examination that focuses on dysmorphic physical findings is performed. Evaluation of children and young adults with hearing loss should follow a similar approach. Evaluation of deaf or hardof-hearing adults should be customized based on the age of onset and other characteristics of the hearing loss (Figure 1).

- The medical and birth histories may be helpful in differentiating between acquired versus inherited causes of hearing loss. Elements of medical and birth histories focused on hearing loss include the following: - Prenatal history, including maternal infections (e.g., CMV, rubella) and illnesses (e.g., syphilis), or medication or drug exposures (e.g., thalidomide, retinoic acid) ${ }^{113,114}$;

- Neonatal history, including premature birth, low birth weight, birth hypoxia, hyperbilirubinemia, sepsis, and exposure to ototoxic medications;

- Postnatal history, including viral illnesses, bacterial meningitis, head trauma, noise exposure, and exposure to ototoxic medications; and

- Audiometric assessment of the hearing loss, including sensorineural versus conductive or mixed hearing loss; age of onset; progressive, nonprogressive, or fluctuating nature of the hearing loss; laterality, symmetry, severity, and configuration of the hearing loss; and the presence or absence of vestibular dysfunction or auditory neuropathy.
- The pedigree and family medical history should focus on identifying the following:

- First- and second-degree relatives with hearing loss or with features commonly associated with hearing loss (such as pigmentary, branchial, or renal anomalies) or sudden cardiac death;

- A pattern of inheritance;

- Ethnicity and country of origin;

- A common origin from ethnically or geographically isolated areas; and

- Consanguinity.

- The physical examination should focus on dysmorphic and other physical findings such as the following:

- Unusual facial appearance, with attention to asymmetry;

- Pigmentary anomalies;

- Neck, skin, facial, or ear anomalies;

- Neurological abnormalities;

- Balance disturbances;

- Skeletal abnormalities; and

- Other unusual physical findings.

2. For individuals with findings that suggest a syndromic genetic etiology for their hearing loss,

- Pretest genetic counseling should be provided, and, with patient's informed consent, genetic testing, if available, should be ordered to confirm the diagnosis-this testing may include single-gene tests, hearing loss sequencing panels, WES, WGS, chromosome analysis, or microarray-based copy-number analysis, depending on clinical findings;

- Appropriate studies should be undertaken to determine whether other organs are involved; and

- Appropriate near-term and long-term screening and management should be arranged, including referrals to specialists, as indicated by the associated manifestations of the particular syndrome.

3. For individuals lacking physical findings suggestive of a known syndrome and having medical and birth histories that do not suggest an environmental cause of hearing loss, a tiered diagnostic approach should be implemented.

- Pretest genetic counseling should be provided, and, with patient's informed consent, genetic testing should be ordered.

- Single-gene testing may be warranted in cases in which the medical or family history, or presentation of the hearing loss, suggests a specific etiology. For example, testing for mitochondrial DNA mutations associated with aminoglycoside ototoxicity may be considered for individuals with a history of use of aminoglycoside antibiotics.

- In the absence of any specific clinical indications and for singleton cases and cases with apparent autosomal recessive inheritance, the next step should be testing for DFNB1-related hearing loss (due to mutations in GJB2 and adjacent deletions in GJB6). 
- If initial genetic testing is negative, genetic testing using gene panel tests, NGS technologies such as large sequencing panels targeted toward hearing loss-related genes, WES, or WGS may be considered. Because several tests are clinically available, the clinician must be aware of the genes included in the test (panel) chosen and the performance characteristics of the platform chosen, including coverage, analytic sensitivity, and what types of mutations will be detected. It should be noted that the cost of these new genetic sequencing technologies is decreasing so rapidly that a tiered approach to testing may soon no longer be cost effective. In particular, for large sequencing panels targeted toward hearing lossrelated genes, it may, in some cases, already be more cost effective to use NGS technologies as the initial test in the evaluation of hearing loss. However, issues related to genomic testing, such as the likelihood of incidental findings, will have to be addressed.

- If genetic testing reveals mutation(s) in a hearing loss-related gene, mutation-specific genetic counseling should be provided, followed by appropriate medical evaluations and referrals.

- If genetic testing fails to identify an etiology for a patient's hearing loss, the possibility of a genetic or acquired etiology remains. This point must be emphasized because it can be misunderstood by clinicians and by patients and their families. For interested patients and families, further genetic testing may be pursued on a research basis.

- Temporal bone imaging by computed tomography or magnetic resonance imaging should be considered as a complement to genetic testing, particularly if the diagnosis remains unclear, if cochlear implantation is being considered, if auditory neuropathy is noted, in cases of progressive hearing loss, or if other clinical concerns exist. The anticipated clinical utility of imaging studies should be balanced against the risks associated with radiation exposure and sedation.

- CMV testing should be done at the same time as genetic testing for infants with congenital hearing loss. For later-onset or progressive hearing loss, CMV testing can be obtained, but the likelihood that a positive test is due to postnatal exposure increases with age.

4. Referral to a multidisciplinary care center, when available, is recommended.

- A team approach that includes otolaryngologists, clinical geneticists, genetic counselors, audiologists, speech and language specialists, early hearing intervention and family support specialists (which may include other individuals who are deaf or hard of hearing or other parents of deaf or hard-of-hearing children), and other appropriate specialists offers optimal opportunity to provide ongoing management and support of deaf and hard-of-hearing individuals and their families as their needs change over time.

- For cases in which the genetic evaluation failed to identify an underlying cause, periodic follow-up care every 3 years with a geneticist may be appropriate for several reasons. First, subtle features of syndromic forms of hearing loss may not be apparent at birth or early in childhood but may appear as deaf or hard-ofhearing individuals grow into adulthood. These may prompt additional medical tests or referrals for specialty care. Second, follow-up visits offer the opportunity to inform individuals about new genetic tests that may have become available or changes in the interpretation of previous test results as medical knowledge advances. Finally, follow-up visits may also help identify clinical concerns unrelated to hearing loss, for which referral for specialty care may be appropriate (Figure 1).

5. Regardless of whether genetic test results are positive, negative, or inconclusive, results should be communicated through the process of genetic counseling.

\section{DISCLOSURE}

C.G.P. has received grant support to develop educational materials on cancer for the Deaf community. H.L.R. is employed by a fee-for-service laboratory that offers diagnostic testing for hearing loss. The other authors declare no conflict of interest.

\section{REFERENCES}

1. Finitzo T, Albright K, O'Neal J. The newborn with hearing loss: detection in the nursery. Pediatrics 1998;102:1452-1460.

2. Yoshinaga-Itano C, Coulter D, Thomson V. Developmental outcomes of children with hearing loss born in Colorado hospitals with and without universal newborn hearing screening programs. Semin Neonatol 2001;6:521-529

3. American Academy of Audiology Childhood Hearing Screening Guidelines. American Academy of Audiology [serial online] 2012; American Academy of Audiology. http://www.cdc.gov/ncbddd/hearingloss/documents/AAA Childhood\%20Hearing\%20Guidelines_2011.pdf. Accessed 12 June 2012.

4. Harlor AD Jr, Bower C; Committee on Practice and Ambulatory Medicine; Section on Otolaryngology-Head and Neck Surgery. Hearing assessment in infants and children: recommendations beyond neonatal screening. Pediatrics 2009;124:1252-1263.

5. Marazita ML, Ploughman LM, Rawlings B, Remington E, Arnos KS, Nance WE. Genetic epidemiological studies of early-onset deafness in the U.S. school-age population. Am J Med Genet 1993;46:486-491.

6. Mitchell RE, Karchmer MA. Chasing the mythical ten percent: parental hearing status of deaf and hard of hearing students in the United States. Sign Lang Studies 2004;4:138-163.

7. Pandya A, Arnos KS, Xia XJ, et al. Frequency and distribution of GJB2 (connexin 26) and GJB6 (connexin 30) mutations in a large North American repository of deaf probands. Genet Med 2003;5:295-303.

8. National Institute on Deafness and Other Communication Disorders (NIDCD): Presbycusis Health Statistics. National Institute on Deafness and Other Communication Disorders [serial online] 2011; http://www.nidcd.nih.gov/ health/hearing/presbycusis.htm. Accessed 12 June 2012.

9. Carlsson PI, Van Laer L, Borg E, et al. The influence of genetic variation in oxidative stress genes on human noise susceptibility. Hear Res 2005;202:87-96.

10. Friedman RA, Van Laer L, Huentelman MJ, et al. GRM7 variants confer susceptibility to age-related hearing impairment. Hum Mol Genet 2009;18:785-796.

11. Op de Beeck K, Schacht J, Van CG. Apoptosis in acquired and genetic hearing impairment: the programmed death of the hair cell. Hear Res 2011;281:18-27. 
12. Unal M, Tamer L, Dogruer ZN, Yildirim H, Vayisoglu Y, Camdeviren $H$ $\mathrm{N}$-acetyltransferase 2 gene polymorphism and presbycusis. Laryngoscope 2005;115:2238-2241.

13. Van Eyken E, Van Camp G, Van Laer L. The complexity of age-related hearing impairment: contributing environmental and genetic factors. Audiol Neurootol 2007:12:345-358.

14. Van Laer L, Van Eyken E, Fransen E, et al. The grainyhead like 2 gene (GRHL2), alias TFCP2L3, is associated with age-related hearing impairment. Hum Mol Genet 2008;17:159-169.

15. Kochhar A, Hildebrand MS, Smith RJ. Clinical aspects of hereditary hearing loss. Genet Med 2007;9:393-408.

16. Pandya A, Arnos KS. Genetic evaluation and counseling in the context of early hearing detection and intervention. Semin Hear 2006;27:205-212.

17. Robin NH, Prucka SK, Woolley AL, Smith RJ. The use of genetic testing in the evaluation of hearing impairment in a child. Curr Opin Pediatr 2005;17: 709-712.

18. American Speech-Language-Hearing Assocation: Degree of Hearing Loss American Speech-Language-Hearing Association (AHSA) [serial online] 2012; American Speech-Language-Hearing Association (AHSA). http://www.asha. org/public/hearing/Degree-of-Hearing-Loss/. Accessed 12 June 2012.

19. Pagon RA, Adam MP, Bird TD, et al., (eds).GeneReviews [Internet] University of Washington: Seattle, WA, 1993-2011. http://www.ncbi.n/m.nih.gov/books/ NBK1116. Accessed 7 February 2014.

20. Hereditary Hearing Loss and Its Syndromes, 3rd edn. Toriello HV, Smith S (eds). Oxford University Press: New York, NY, 2013.

21. Van Camp G, Smith RJ. Hereditary Hearing Loss Homepage. Hereditary Hearing Loss Homepage [serial online] 2011; http://hereditaryhearingloss.org. Accessed 12 June 2012

22. Kimberling WJ, Hildebrand MS, Shearer AE, et al. Frequency of Usher syndrome in two pediatric populations: implications for genetic screening of deaf and hard of hearing children. Genet Med 2010;12:512-516.

23. Park HJ, Shaukat S, Liu XZ, et al. Origins and frequencies of SLC26A4 (PDS) mutations in east and south Asians: global implications for the epidemiology of deafness. J Med Genet 2003;40:242-248

24. Smith RJH. Branchiootorenal Spectrum Disorders. GeneReviews [serial online] 1993; PMID:20301554. University of Washington, Seattle, WA. http://www. ncbi.nlm.nih.gov/books/NBK1380. Accessed 26 November 2013

25. Yuan Y, Guo W, Tang J, et al. Molecular epidemiology and functional assessment of novel allelic variants of SLC26A4 in non-syndromic hearing loss patients with enlarged vestibular aqueduct in China. PLOS ONE 2012;7:e49984.

26. Schultz JM. Waardenburg syndrome. Semin Hear 2006;27:171-181.

27. Madeo AC, Pryor SP, Brewer $C$ et al. Pendred syndrome. Semin Hear 2006:27:160-170.

28. Bamiou DE, Savy L, O'Mahoney C, Phelps P, Sirimanna T. Unilateral sensorineural hearing loss and its aetiology in childhood: the contribution of computerised tomography in aetiological diagnosis and management. Int J Pediatr Otorhinolaryngol 1999:51:91-99.

29. Dodson KM, Georgolios A, Barr N, et al. Etiology of unilateral hearing loss in a national hereditary deafness repository. Am J Otolaryngol 2012;33:590594.

30. Li Z, Li R, Chen J, et al. Mutational analysis of the mitochondrial $12 \mathrm{~S}$ rRNA gene in Chinese pediatric subjects with aminoglycoside-induced and non-syndromic hearing loss. Hum Genet 2005;117:9-15.

31. Pandya A, Xia X, Radnaabazar J, et al. Mutation in the mitochondrial 125 rRNA gene in two families from Mongolia with matrilineal aminoglycoside ototoxicity. J Med Genet 1997;34:169-172.

32. Abe S, Usami S, Shinkawa H, Kelley PM, Kimberling WJ. Prevalent connexin 26 gene (GJB2) mutations in Japanese. J Med Genet 2000;37:41-43.

33. Denoyelle F, Marlin S, Weil D, et al. Clinical features of the prevalent form of childhood deafness, DFNB1, due to a connexin-26 gene defect: implications for genetic counselling. Lancet 1999;353:1298-1303.

34. Estivill $X$, Fortina $P$, Surrey $S$, et al. Connexin-26 mutations in sporadic and inherited sensorineural deafness. Lancet 1998;351:394-398.

35. Kelsell DP, Dunlop J, Stevens HP, et al. Connexin 26 mutations in hereditary nonsyndromic sensorineural deafness. Nature 1997;387:80-83.

36. Kenneson A, Van Naarden Braun K, Boyle C. GJB2 (connexin 26) variants and nonsyndromic sensorineural hearing loss: a HuGE review. Genet Med 2002:4:258-274

37. Kudo T, Ikeda K, Kure S, et al. Novel mutations in the connexin 26 gene (GJB2) responsible for childhood deafness in the Japanese population. Am J Med Genet 2000;90:141-145.

38. RamShankar M, Girirajan S, Dagan O, et al. Contribution of connexin26 (GJB2) mutations and founder effect to non-syndromic hearing loss in India. J Med Genet 2003;40:e68.
39. Chan DK, Schrijver I, Chang KW. Connexin-26-associated deafness: phenotypic variability and progression of hearing loss. Genet Med 2010:12:174-181.

40. Kenna MA, Feldman HA, Neault MW, et al. Audiologic phenotype and progression in GJB2 (Connexin 26) hearing loss. Arch Otolaryngol Head Neck Surg 2010;136:81-87

41. Norris VW, Arnos KS, Hanks WD, Xia X, Nance WE, Pandya A. Does universal newborn hearing screening identify all children with GJB2 (Connexin 26) deafness? Penetrance of GJB2 deafness. Ear Hear 2006;27:732-741.

42. Snoeckx RL, Huygen PL, Feldmann D, et al. GJB2 mutations and degree of hearing loss: a multicenter study. Am J Hum Genet 2005;77:945-957.

43. del Castillo FJ, Rodríguez-Ballesteros $\mathrm{M}$, Alvarez $\mathrm{A}$, et al. A novel deletion involving the connexin-30 gene, del(GJB6-d13s1854), found in trans with mutations in the GJB2 gene (connexin-26) in subjects with DFNB1 nonsyndromic hearing impairment. J Med Genet 2005;42:588-594.

44. del Castillo I, Villamar M, Moreno-Pelayo MA, et al. A deletion involving the connexin 30 gene in nonsyndromic hearing impairment. N Engl J Med 2002;346:243-249.

45. Del Castillo I, Moreno-Pelayo MA, Del Castillo FJ, et al. Prevalence and evolutionary origins of the del(GJB6-D13S1830) mutation in the DFNB1 locus in hearing-impaired subjects: a multicenter study. Am J Hum Genet 2003;73:1452-1458.

46. Feldmann D, Denoyelle F, Chauvin P, et al. Large deletion of the GJB6 gene in deaf patients heterozygous for the GJB2 gene mutation: genotypic and phenotypic analysis. Am J Med Genet A 2004;127A:263-267.

47. Fitzgerald T, Duva S, Ostrer $\mathrm{H}$, et al. The frequency of GJB2 and GJB6 mutations in the New York State newborn population: feasibility of genetic screening for hearing defects. Clin Genet 2004;65:338-342.

48. Palmer CG, Martinez A, Fox M, et al. A prospective, longitudinal study of the impact of GJB2/GJB6 genetic testing on the beliefs and attitudes of parents of deaf and hard-of-hearing infants. Am J Med Genet A 2009;149A:1169-1182.

49. de Zwart-Storm EA, van Geel M, Veysey E, et al. A novel missense mutation in GJB2, p.Tyr65His, causes severe Vohwinkel syndrome. Br J Dermatol 2011;164:197-199.

50. lossa S, Marciano E, Franzé A. GJB2 Gene Mutations in Syndromic Skin Diseases with Sensorineural Hearing Loss. Curr Genomics 2011:12:475-785.

51. Richard G, Rouan F, Willoughby CE, et al. Missense mutations in GJB2 encoding connexin-26 cause the ectodermal dysplasia keratitis-ichthyosis-deafness syndrome. Am J Hum Genet 2002;70:1341-1348.

52. Pandya A. Nonsyndromic Hearing Loss and Deafness, Mitochondrial. 22 October 2004 [updated 21 April 2011]. In: Pagon RA, Adam MP, Bird TD, et al. (eds). GeneReviews [Internet] University of Washington: Seattle, WA, 1993-2014. http://www.ncbi.nlm.nih.gov/books/NBK1422. Accessed 7 February 2014.

53. Estivill $X$, Govea N, Barceló $E$, et al. Familial progressive sensorineural deafness is mainly due to the mtDNA A1555G mutation and is enhanced by treatment of aminoglycosides. Am J Hum Genet 1998;62:27-35.

54. Prezant TR, Agapian JV, Bohlman MC, et al. Mitochondrial ribosomal RNA mutation associated with both antibiotic-induced and non-syndromic deafness. Nat Genet 1993;4:289-294.

55. Rahman S, Ecob R, Costello H, et al. Hearing in 44-45 year olds with m.1555A $>\mathrm{G}$, a genetic mutation predisposing to aminoglycoside-induced deafness: a population based cohort study. BMJ Open 2012;2:e000411

56. Morton NE. Genetic epidemiology of hearing impairment. Ann N Y Acad Sci 1991;630:16-31.

57. Davis RR, Kozel P, Erway LC. Genetic influences in individual susceptibility to noise: a review. Noise Health 2003;5:19-28.

58. Tak S, Davis RR, Calvert GM. Exposure to hazardous workplace noise and use of hearing protection devices among US workers-NHANES, 1999-2004. Am J Ind Med 2009;52:358-371.

59. Grosse SD, Ross DS, Dollard SC. Congenital cytomegalovirus (CMV) infection as a cause of permanent bilateral hearing loss: a quantitative assessment. J Clin Virol 2008;41:57-62.

60. Dollard SC, Grosse SD, Ross DS. New estimates of the prevalence of neurological and sensory sequelae and mortality associated with congenital cytomegalovirus infection. Rev Med Virol 2007:17:355-363.

61. Yamamoto AY, Mussi-Pinhata MM, Isaac Mde L, et al. Congenital cytomegalovirus infection as a cause of sensorineural hearing loss in a highly immune population. Pediatr Infect Dis J 2011:30:1043-1046.

62. Morton CC, Nance WE. Newborn hearing screening-a silent revolution. N Engl $J$ Med 2006;354:2151-2164

63. Reef SE, Redd SB, Abernathy E, Kutty P, Icenogle JP. Evidence used to support the achievement and maintenance of elimination of rubella and congenital rubella syndrome in the United States. J Infect Dis 2011;204(suppl 2):S593-S597. 
64. Plotkin SA. The history of rubella and rubella vaccination leading to elimination. Clin Infect Dis 2006;43(suppl 3):S164-S168.

65. Rubella: Fact sheet No. 367. World Health Organization [serial online] 2012; http://www.who.int/mediacentre/factsheets/fs367/en/. Accessed 29 November 2013.

66. Stein LK, Boyer KM. Progress in the prevention of hearing loss in infants. Ear Hear 1994;15:116-125.

67. Fligor BJ, Neault MW, Mullen CH, Feldman HA, Jones DT. Factors associated with sensorineural hearing loss among survivors of extracorporeal membrane oxygenation therapy. Pediatrics 2005;115:1519-1528.

68. Marlow ES, Hunt LP, Marlow N. Sensorineural hearing loss and prematurity. Arch Dis Child Fetal Neonatal Ed 2000;82:F141-F144.

69. Robertson CM, Howarth TM, Bork DL, Dinu IA. Permanent bilateral sensory and neural hearing loss of children after neonatal intensive care because of extreme prematurity: a thirty-year study. Pediatrics 2009;123:e797-e807.

70. Boudreault P, Baldwin EE, Fox M, et al. Deaf adults' reasons for genetic testing depend on cultural affiliation: results from a prospective, longitudinal genetic counseling and testing study. J Deaf Stud Deaf Educ 2010;15:209-227.

71. Brunger JW, Murray GS, O'Riordan M, Matthews AL, Smith RJ, Robin NH. Parental attitudes toward genetic testing for pediatric deafness. Am J Hum Genet 2000;67:1621-1625.

72. Burton SK, Withrow K, Arnos KS, Kalfoglou AL, Pandya A. A focus group study of consumer attitudes toward genetic testing and newborn screening for deafness. Genet Med 2006;8:779-783.

73. Palmer CG, Martinez A, Fox M, Sininger Y, Grody WW, Schimmenti LA. Ethnic differences in parental perceptions of genetic testing for deaf infants. J Genet Couns 2008;17:129-138.

74. Palmer CG, Boudreault P, Baldwin EE, et al. Deaf genetic testing and psychological well-being in deaf adults. J Genet Couns 2013;22:492-507.

75. Robin NH. Medical Genetics: Its Application to Speech, Hearing, and Craniofacial Disorders. Plural Publishing: San Diego, California, 2008.

76. Robin NH. It does matter: the importance of making the diagnosis of a genetic syndrome. Curr Opin Pediatr 2006;18:595-597.

77. Withrow KA, Burton S, Arnos KS, Kalfoglou A, Pandya A. Consumer motivations for pursuing genetic testing and their preferences for the provision of genetic services for hearing loss. J Genet Couns 2008;17:252-260.

78. Withrow KA, Tracy KA, Burton SK, et al. Impact of genetic advances and testing for hearing loss: results from a national consumer survey. Am J Med Genet $A$ 2009;149A:1159-1168

79. Withrow KA, Tracy KA, Burton SK, et al. Provision of genetic services for hearing loss: results from a national survey and comparison to insights obtained from previous focus group discussions. J Genet Couns 2009;18:618-621.

80. Middleton A, Palmer CGS. Clients who are D/deaf or hard of hearing. In: Wiggins J, Middleton A (eds). Getting the Message Across: Communication with Diverse Populations in Clinical Genetics. Oxford University Press: Oxford, UK, 2012.

81. Lane H. Ethnicity, ethics, and the deaf-world. J Deaf Stud Deaf Educ 2005;10:291-310.

82. Padden CA, Humphries TL. Deaf in America: Voices from a Culture. Harvard University Press: Cambridge, MA, 1988.

83. Martinez A, Linden J, Schimmenti LA, Palmer CG. Attitudes of the broader hearing, deaf, and hard-of-hearing community toward genetic testing for deafness. Genet Med 2003;5:106-112.

84. Middleton A, Hewison J, Mueller RF. Attitudes of deaf adults toward genetic testing for hereditary deafness. Am J Hum Genet 1998;63:1175-1180.

85. Sankar P, Cho MK, Wolpe PR, Schairer C. What is in a cause? Exploring the relationship between genetic cause and felt stigma. Genet Med 2006; 8:33-42.

86. Baldwin EE, Boudreault P, Fox M, Sinsheimer JS, Palmer CG. Effect of pre-test genetic counseling for deaf adults on knowledge of genetic testing. J Genet Couns 2012;21:256-272.

87. Middleton A, Emery SD, Turner GH. Views, knowledge, and beliefs about genetics and genetic counseling among deaf people. Sign Lang Studies 2010;10:170-196.

88. Arnos KS, Cunningham M, Israel J, Marazita ML. Innovative approach to genetic counseling services for the deaf population. Am J Med Genet 1992;44: 345-351.

89. Israel J, Cunningham M, Thumann H, Arnos KS. Genetic counseling for deaf adults: Communication/language and cultural considerations. J Genet Couns 1992;1:135-153.

90. Bonnet C, Grati M, Marlin S, et al. Complete exon sequencing of all known Usher syndrome genes greatly improves molecular diagnosis. Orphanet J Rare Dis 2011:6:21.
91. Usami S, Nishio SY, Nagano M, Abe S, Yamaguchi T; Deafness Gene Study Consortium. Simultaneous screening of multiple mutations by invader assay improves molecular diagnosis of hereditary hearing loss: a multicenter study. PLOS ONE 2012;7:e31276

92. Brown KK, Rehm HL. Molecular diagnosis of hearing loss. Curr Protoc Hum Genet 2012;72:9.16.1-9.16.16.

93. Brownstein Z, Friedman LM, Shahin $\mathrm{H}$, et al. Targeted genomic capture and massively parallel sequencing to identify genes for hereditary hearing loss in Middle Eastern families. Genome Biol 2011;12:R89.

94. Shearer AE, DeLuca AP, Hildebrand MS, et al. Comprehensive genetic testing for hereditary hearing loss using massively parallel sequencing. Proc Natl Acad Sci USA 2010;107:21104-21109.

95. Shearer AE, Hildebrand MS, Sloan CM, Smith RJ. Deafness in the genomics era. Hear Res 2011;282:1-9.

96. Sirmaci A, Edwards YJ, Akay H, Tekin M. Challenges in whole exome sequencing: an example from hereditary deafness. PLOS ONE 2012; 7:e32000

97. GeneTests: Medical Genetics Information Resource (database online). University of Washington, Seattle, WA, 1993-2011 [serial online] 2012. http://www. genetests.org. Accessed 30 June 2011

98. GTR: Genetic Testing Registry. National Center for Biotechnology Information, US National Library of Medicine [serial online] 2012;http://www.ncbi.nIm.nih. gov/gtr/. Accessed 25 September 2012.

99. Rehm HL, Bale SJ, Bayrak-Toydemir P, et al.; Working Group of the American College of Medical Genetics and Genomics Laboratory Quality Assurance Committee. ACMG clinical laboratory standards for next-generation sequencing. Genet Med 2013;15:733-747.

100. Green RC, Berg JS, Grody WW, et al. ACMG recommendations for reporting of incidental findings in clinical exome and genome sequencing. Genet Med 2013;15:565-574.

101. Boppana SB, Ross SA, Shimamura M, et al.; National Institute on Deafness and Other Communication Disorders CHIMES Study. Saliva polymerasechain-reaction assay for cytomegalovirus screening in newborns. N Engl I Med 2011;364:2111-2118.

102. Lombardi G, Garofoli F, Stronati M. Congenital cytomegalovirus infection: treatment, sequelae and follow-up. J Matern Fetal Neonatal Med 2010;23(supp 3):45-48.

103. Rosenthal LS, Fowler KB, Boppana SB, et al. Cytomegalovirus shedding and delayed sensorineural hearing loss: results from longitudinal followup of children with congenital infection. Pediatr Infect Dis J 2009;28: 515-520.

104. Shin JJ, Keamy DG Jr, Steinberg EA. Medical and surgical interventions for hearing loss associated with congenital cytomegalovirus: a systematic review. Otolaryngol Head Neck Surg 2011;144:662-675.

105. Yamamoto AY, Mussi-Pinhata MM, Marin LJ, Brito RM, Oliveira PF, Coelho TB. Is saliva as reliable as urine for detection of cytomegalovirus DNA for neonatal screening of congenital CMV infection? J Clin Virol 2006; 36:228-230.

106. Cohen M, Phillips JA 3rd. Genetic approach to evaluation of hearing loss. Otolaryngol Clin North Am 2012;45:25-39.

107. Reardon W, OMahoney CF, Trembath R, Jan H, Phelps PD. Enlarged vestibular aqueduct: a radiological marker of pendred syndrome, and mutation of the PDS gene. QJM 2000;93:99-104.

108. Lai R, Hu P, Zhu F, et al. Genetic diagnosis and cochlear implantation for patients with nonsyndromic hearing loss and enlarged vestibular aqueduct. J Laryngol Otol 2012;126:349-355.

109. Lin JW, Chowdhury N, Mody A, et al. Comprehensive diagnostic battery for evaluating sensorineural hearing loss in children. Otol Neurotol 2011;32:259264.

110. Madden C, Halsted M, Meinzen-Derr J, et al. The influence of mutations in the SLC26A4 gene on the temporal bone in a population with enlarged vestibular aqueduct. Arch Otolaryngol Head Neck Surg 2007;133:162168.

111. Chiang CE. Congenital and acquired long QT syndrome. Current concepts and management. Cardiol Rev 2004;12:222-234.

112. Tranebjaerg L, Samson RA, Green GE. Jervell and Lange-Nielsen Syndrome. GeneReviews [serial online] 2010; PMID:20301579. University of Washington, Seattle, WA. http://www.ncbi.nlm.nih.gov/books/NBK1405. Accessed 15 June 2012.

113. Dyer JJ, Strasnick B, Jacobson JT. Teratogenic hearing loss: a clinical perspective. Am J Otol 1998;19:671-678.

114. Takemori S, Tanaka Y, Suzuki Jl. Thalidomide anomalies of the ear. Arch Otolaryngol 1976;102:425-427. 